This is the Author's version. The final publication is in Journal of English for Academic Purposes (March 2015), available at Elsevier via

http://www.sciencedirect.com/science/article/pii/S1475158515000089

\title{
Personal Statement in PhD applications: Gatekeepers' evaluative perspectives
}

\author{
Yuan-Li Tiffany Chiu \\ King's College London, UK, yuan-li.chiu@kcl.ac.uk
}

\begin{abstract}
This paper explores academic readers' views of the doctoral Personal Statements (PSs) written by student applicants across institutional contexts. The analysis was based on in-depth semistructured interviews with 19 faculty members involved in evaluating the $\mathrm{PhD}$ applications within Education at one UK-based and one US-based university. Data were coded by NVivo software and then analysed using methods drawn from critical discourse analysis and conversation analysis to unravel participant intended meaning. Results suggest that the situated knowledge of institutional settings where these academics are based will affect the ways in which they act and think in relation to particular forms of discourse. Specifically, the UK and US academics' interpretations of PSs and its associated evaluation practices are related to their conceptual understanding of the culture of doctoral level study and the structure of the admissions process in their own particular academic community. The paper concludes with some pedagogical implications and a discussion of potential areas for further study to investigate the 'academic' and 'rhetorical' aspects of the PS and to understand the different and often implicit features of the PS across different disciplines, programmes, and institutional contexts.
\end{abstract}

Keywords: personal statement; $\mathrm{PhD}$ application; discourse; reader perceptions; interviews; institutional contexts

\section{Introduction}

Over the last decade, many studies in ESP/EAP have adopted a genre-based approach to analyse different types of academic writing in a particular context (Hyland \& Tse, 2005; Swales \& Leeder, 2012). In comparison with other academic publications, such as dissertations and research articles, Personal statements (PS, or known as the Statement of Purpose, SOP) for admission to higher education institutions have received relatively less attention. Applicants are often asked to provide information in their statements, such as reasons for pursuing the studies and relevant experiences and achievements while they may have little idea of what piece of information should be included within the given word limit, or what voice will best meet potential audiences' expectations. The PS, however, differs from the conventional student essay/assignment within an academic setting because it is written by students who have not yet become members of the target academic discourse community and it is this threshold level to the outsiders (Swales, 1990, pp. 24-27) that has intensified difficulty in composing this text.

Many postgraduate university applications in the USA and UK require applicants to submit PSs along with other application documents. For example, for doctoral applications made to USbased universities, students are usually required to submit several documents via an online 
application system, including their PS, application form, a resume, letters of recommendation, academic transcripts from previous higher education institutions that students have attended, an official copy of their standardised test scores for the GRE (Graduate Record Examination) and, if they are international applicants (with the exception of those who hold an undergraduate degree from a university where English is the primary language of instruction), they will also need to submit their TOEFL (Test of English as a Foreign Language) or IELTS (International English Language Testing System) results. For doctoral programmes in the UK, applicants are often asked to submit their application form, a PS that is often incorporated as part of the application form, research proposal, references, transcripts of each academic degree(s), and IELTS or TOEFL scores (if English is not their first language). A sample of student previous written work (usually 15-20 pages, 5,000 - 7,000 words) may be required in both contexts, depending on different programmes involved. Here, it should be noted that for PhD studies in the UK-based institutions, it is commonly the case that as soon as students are accepted into the doctoral programme of study, they will be expected to work on their individual research project. A research proposal is required before entry, which covers areas such as proposed research topics/questions, theory, methodology and timescale, albeit it tends to be fine-tuned as students commence on their project. Unlike the UK doctoral applications, doctoral students at US-based universities are not generally expected to conduct their independent research project as soon as they begin a course of study. They usually need to undertake a number of course units in the first two years, and work with faculty members within the department as a research and/or teaching assistant.

The existing studies on the PS have mostly adopted Swales' rhetorical move-step analysis and/or discourse analysis to identify rhetorical features. It is clear that different textual features and rhetorical structures are identifiable across different programmes of study. For example, Brown (2004) examined the PSs by students that were admitted, against those who were rejected in the context of clinical psychology doctoral admissions. Combining quantitative and qualitative methods, he coded and analysed a selection of 18 PSs (9 successful and 9 unsuccessful). The findings revealed that the successful applicants dedicated more space to expressing their research aims and constructing research scientist identity, and included far fewer details of personal lives. Brown (2004) reported that one interviewee stated that strong candidates are those who "think like a scientist" (p. 251). In contrast to the results outlined in Brown's study, Bekins, Huckin, and Kijak (2004) found that the PSs for medical school applications tend to focus more on applicants' practical experiences and how those experiences have contributed to their career choice, rather than on research-oriented information. In other words, the use of retrospective kind of accounts that concern students' reflection of their past experiences appears to be desirable as examiners tend to use this type of information to gauge applicant interests and qualities for succeeding in the medicine programmes. The results of Bekins et al.'s study were consistent with those of Barton, Ariail, and Smith (2004) in which they looked at 169 PSs for medical residency applications at a US-based university. Barton et al. (2004) revealed that applicants' attempt to present themselves in the way that will match between applicants' relevant selves (e.g., a memorable self, an accomplished self) and the reader reception is a complex process.

Further, the variations of PSs across disciplines have been examined by Samraj and Monk (2008) in which they analysed rhetorical structures of the PSs submitted to three master's departments at a US-based university (Linguistics; Business administration; and Electrical engineering) and 
interviewed disciplinary specialists to complement the results of the text analysis. The results indicated that the generic structure of PSs from the three disciplines consists of similar rhetorical moves but differ in the associated steps. Unlike Brown's (2004) study on the doctoral programme in psychology, Samraj and Monk (2008) revealed that the 'step of research focus' is not so apparent in their PS corpus apart from the Engineering statements. Amongst the few studies, Ding (2007) appears to be the one (if any) focusing on both move analysis and an analysis of lexical features of the PSs in which 30 online PSs (20 successful and 10 unsuccessful or unedited PSs) from medical/dental schools were collected from public websites. The findings suggested that compared with successful PSs, unedited ones tend to include irrelevant personal stories which do not make an explicit connection between their stories and the purpose of applying for medical schools.

Although these studies have contributed to the understanding of disciplinary epistemology, other challenges that applicants often face are the opaque admissions process in which the different and often implicit considerations of academics, based on departmental and institutional conditions, may influence the way the applications are evaluated. For instance, Samraj and Monk (2008) have pointed out that some of the faculty whom they interviewed stated that "the quality of the statement would generally be in line with the judgments that the admissions committee reached based on the other admission information such as graduate record examination scores and letters of recommendation" (p. 199). Feak also commented that writing a PS is a "tough thing, because it filters into all sorts of things other than just the [Personal Statements], things like trying to understand the admissions process in general" (cited in Barton \& Brown, 2004, p. 11 ). It is also believed that the evaluation practice can vary depending on the structure of the individual programmes. For instance, Brown (2004) stated that the adoption of 'mentor system' within the psychology department has given faculty members the power to choose their own students and hence positioned the PS an important role for the judgement about an applicant's suitability and matchness rather than merely using the GRE score that was previously the greatest indication of a successful application. As such, the role of the PS in admissions may not be straightforward, which echoes Lea and Street's (1998) views in that "what constitutes valid knowledge within a particular context, and the relationships of authority that exist around the communication" (p. 170) have affected the process of meaning-making given to students' writing and often these assumptions remain implicit to student writers.

On the basis of this discussion, it can then be argued that the PS has to be understood with respect to other complex issues such as reader expectations, institutional practices, power relationships and epistemological assumptions for specific level of study and within a particular academic community. None of the studies appear to have focused on the practices and conventions associated with the PS across institutional contexts. This present study moves on to explore faculty members' views and evaluation practices towards PSs submitted to $\mathrm{PhD}$ programmes within the field of Education at one UK-based and one US-based university. The consideration of UK- and US- based contexts is informed by Russell et al.'s (2009) article that discussed writing and literacy practices in terms of institutional position of writing in various educational systems across countries. They illustrated some educational situations existing in the UK and US and how that may influence the ways in which writing practice has been shaped and developed. Informed by their discussion, the focus of the current study on the two distinct 
educational contexts provides a range of empirical opportunities to investigate the PS genre. This study explores the following empirical questions:

1. What are the interpretations and perceptions of the PS that have been formed by faculty members at the UK-based and US-based universities?

2. Are there any institutional variations with regards to evaluation practices associated with the PS at the two focal universities? If so, how have these variations in practices enabled and constrained meaning-making associated with the PS?

\section{The study}

\subsection{Participants and data}

This study conducts an exploratory qualitative investigation of faculty members' views on PSs and the relevant evaluation practices. In doing so it draws on 'ethnographic sensibilities' that focuses on the meanings, perceptions and interpretations of the subject being studied from insider or emic point of view. Here, the expression of 'ethnographic sensibilities' entails a more neutral position with the attempt to unveil participant-oriented meaning from academic insider perspectives while remaining aware of being different from 'doing ethnography' in its full sense that involves long-term immersion and engagement in the field of study (Green \& Bloome, 1997). Given the purpose of this study and the resources available, in-depth semi-structured interviews were used to explore the ways in which the academics evaluated PSs. Data used in this study comprise 9 academics from a UK-based institution and 10 from a US-based one. I approached these academics via email that was listed on the institution's website. Both universities were considered as elite and research-intensive. Here, it should be noted that in order to help contextualise and broaden the scope of my findings, a range of academics with varied specialisms within the field of Education were recruited from the two focal institutions (see Table 1 for documentation of each academic's expertise). Although the primary focus of this study is an exploration of institutional variations, any interesting differences across specialisms within Education that emerged through the analysis will be noted.

Table 1 Academic participants at the two focal universities

\begin{tabular}{|l|l|l|l|}
\hline \multicolumn{2}{|l|}{ UK academics } & US academics \\
\hline Pseudonym & Research areas & Pseudonym & Research areas \\
\hline Steven & Language and Literacy & Ariel & Educational Linguistics \\
\hline Jason & Language and Literacy & Michelle & Educational Linguistics \\
\hline Bill & Language and Literacy & Carol & Educational Linguistics \\
\hline Sam & Education Policy & Vicky & Educational Linguistics \\
\hline Betty & Education Policy & Christine & Reading, Writing and Literacy \\
\hline Grace & Education Policy & Max & Higher Education \\
\hline Susan & STEM Education & Jennifer & Higher Education \\
\hline Alex & STEM Education & Sally & Higher Education \\
\hline George & Psychology and Cognitive & Allen & Policy Research \\
\cline { 3 - 4 } & & Roy & Policy Research \\
\hline
\end{tabular}

The interview schedule involved two stages. In order to gain insight into the position of the PS during the admissions process, and hence reach a better interpretation of this type of text, the first stage of the interview involved two broad topic areas: (1) the general admissions process at the 
institution where the academics are based; (2) academics' perceptions of the different parts of the application documentation (e.g., PS, application form, research proposal, academic transcripts, references) and their relations to each other. The second stage of the interview focused on the academics' comments on students' PSs ('talk around text'), with the aim of achieving a range of "[reader] insiders' comments, perspectives, and discourses" (Lillis, 2008, p. 360). The academics were advised to comment on these PSs freely. Those who agreed to participate in my research were asked to read a couple of students' PSs that were sent to them prior to the interviews and then asked to provide their comments on these texts during the interview. The PSs which were sent to the academics were provided by the students at the two focal institutions. As the students and academics belonged to the same institutions, I chose 'mix and match' approach in response to the ethical considerations. Specifically, I was aware that some academics might be able to identify certain students from having previously evaluated their PSs and it is such a situation that might generate some hesitation and unease when the academics were invited to comment on these texts by students with whom they already had some form of professional association. The academics were given the PS texts written by students who did not share the same research topic area as them. All the interviews were conducted face-to-face at the focal institutions. Each interview lasted around 60 minutes and was audio-recorded.

\subsection{Data analysis}

All interviews were transcribed verbatim for analysis and where appropriate, salient paralinguistic features (e.g., stress, intonation) were also noted in the transcripts. In this study, interviews are viewed as a form of 'social action' (Baker \& Johnson, 1998), in keeping with the ethnographic sensibilities. My data analysis employed discourse analytic approaches which take account of both content and ways of talking from which inferences could be drawn regarding the participants' meaning. The idea of 'discourses' in this study is conceptualised as "patterns of belief and habitual action as well as patterns of language" (Johnstone, 2008, p. 3). In light of this, some analytic lenses from critical discourse analysis (CDA, Dick, 2004; Fairclough, 2003) and conversation analysis (CA, Heritage, 2005; Roberts, n.d.) were adopted to explore informants' own meaning.

From CDA, I drew on the lens of 'identifying discourses' to "identify social constructions that have regulatory effects, and which, to some extent, are presented as [...] common sense features of the social domain that is being researched" (Dick, 2004, p. 206). The 'discourses' in this case involve the representation of ideas that academics draw on and take for granted for the purpose of evaluating PS documents for PhD study admissions. Given that CDA aims not to "present any such stabilities as objective features of that domain, but to carefully examine how those stabilities are reproduced or changed" (ibid. p. 206), then the 'discourses' identified in this study cannot be seen as stable or uniform as they may change over time or encompass alternative or competing discourses. To explore the relationship between individual epistemology and institutional requirements, I also drew on Foucault's notion of 'power' which is constituted within discourses and "it is through discourse that disciplinary power exerts its effects at the level of the individual" (ibid. p. 203).

From CA, attention was given to the pattern of participant talking in relation to the uses of lexical choice and other mechanisms of talk (e.g. turn design) across data sets within particular institutional contexts (Heritage, 2005). In her article on qualitative research methods, Roberts 
(n.d.) draws attention to Cicourel's useful distinction between a 'broad' and 'local' context in which "narrow/local context is the context of the interaction itself [...] and 'broad' context includes all the ethnographic information about the institution, including "participant attributes"" (p. 15). The 'local' context in relation to the interview data usually entails the interaction between the researcher (interviewer) and interviewees which generally takes the form of a question-answer pattern. The 'broad' context in this study is associated with the positions/identities of the participants as admissions tutors, and also the institutions where they are based. For example, when individual academics discuss the admissions selection procedure in the interviews, their position has made them aware of "what to say, how to say it, and what others should take it to mean" (Johnstone, 2008, p. 128).

The interview data were first coded inductively before applying analytic concepts drawn from CDA and CA and this proved extremely useful as it allowed me to "divide longer stretches of discourse into parts" (Johnstone, 2008, p. 4) for further comparison and analysis. To assist with this analysis, I used qualitative research software NVivo 10 to help sort and code data systematically, with the aim of identifying recurring/significant themes or concepts.

Concurrently, analytic concepts from CDA and CA were applied as lenses for exploring relevant discourses at both levels of what academics have said ('propositions') and how it has been said ('language in use'). To enhance the reliability of the coding frame, one of my colleagues was asked to code two academic transcripts manually and come up with a coding category for the purpose of comparing and fine-tuning the categorisation (see Burnard, 1991).

In this study, PS texts were taken as subsidiary data to complement the discussion drawing mostly on interview materials. Where necessary, PS extracts on which academics made comments were probed with a primary analytic focus which aims to understand what goal the text is aiming to achieve and how it is constructed to achieve that aim (Fairclough, 1992).

\section{Findings and discussion}

\subsection{Common themes across the two focal institutional contexts}

In terms of the content of the PS, most of the academics at both universities hope to see students' motivation for their proposed field of study and evidence of their relevant experiences and backgrounds that relates to their current area of interest. Some of the academics' accounts are as follows:

(1)

01 Steve: I'm looking for someone who knows what they're letting themselves in for because it requires a huge amount of commitment, sustained effort, and belief in the subject, real motivation and investment in the subject, not just because they want a qualification, it's not a qualification as such. I see it as something very, very different from most of the other academic qualifications that people study for. It's not something that just study and pass, it becomes your life for a few years.

(2)

01 Max: I pay attention to whether there are any particular achievements that they have 02 been able to point out, you know, sort of things that they have done or 
When applying the lens of 'identifying discourse' from CDA (Dick, 2004) to the academics' accounts above as well as others in the data set, a particular discourse that academics at the focal institutions commonly use to construct the nature of evaluation practices can be identified. Such a discourse promotes the view that the admissions evaluation is mainly concerned with applicant compatibility (issue of 'fit') in reference to whom they perceive to be a suitable candidate. This view is itself associated with the academics' perceptions of the nature of $\mathrm{PhD}$ studies ('requires a huge amount of commitment') within particular disciplines and academic communities. Many academics are also concerned with applicant's achievements and relevant experiences and background in relation to the field of education. This echoes the brief instructions on the focal UK-based university's website where applicants are advised to have teaching/professional qualification or equivalent experience and research experience for entry requirements. Steve's account above also echoes his comments on a student's (Anna) opening paragraph in her PS regarding her desire to pursue knowledge:

Student's PS text

I cannot find any better way to start this statement than with a quotation by Socrates: 'the only thing I know is that I know nothing' ( $\varepsilon v$ oi $\delta \alpha$ ótı ov $\delta \varepsilon \dot{v}$ oi $\delta \alpha$ ). His words nicely express my profound beliefs on spiritual cultivation and my desire for expanding my knowledge continuously and persistently.

Academic's interview comment on student PS

01 Steve: Now as soon as if someone mentions 'Socrates' in the first in the opening of their

02 personal statement, I think they are simply trying to impress... which raises

03 suspicions. If I think someone's simply quoting names, yeah, that people see as

04 intellectual names, then I might think, well, what they are trying to mask here?

05 They're trying to impress with this kind of citation by masking the lack of

06 substance in their writing. So that puts me off for a start.

As can be seen from the example above, the student used Socrates' words and at the same time aligned herself with this quotation to show herself as a person who has 'profound beliefs on spiritual cultivation' and is eager to gain knowledge. However, the academic's comment above suggests that the use of the Socrates' quotation engendered a negative image ('trying to impress', 'raises suspicions'). Many other academics also took a similar view. In fact, the use of quotations in students' PSs has triggered the academics' attention and aroused varied interpretations of those quotes in most of the interviews when the academics read and commented on the students' PSs. Here is the other example where one of the academics commented on a student's (Tommy) text:

Student's PS text

The words from the movie "Dead Poets Society", spoken by Dr. Keating (played by Robin Williams), "We all have a great need for acceptance. But you must trust that your beliefs are unique, your own. You need to strive for your own voice because the later you start, the less likely you will find it at all. Two roads diverged in a wood and I, I took the one less travelled by, 
and that has made all the difference", resonated deeply within me. [...] Education system should enable [students] to inspire the society with their diversity, not let them be assimilated.

Academic's interview comment on student PS

01 Allen: I thought it was really, really bad to be citing the movie. We like primary

02 sources... this is a second-hand... or third! (laughs) So they didn't seem, you

03 know, it seemed cute. But we're not about cute, we're about scholarship.

As can be seen from the example above, the student used the quote of an actor in the film 'Dead Poets Society' to align himself with the philosophy of education depicted in the film. However, such an attempt to show his 'passion' and 'motivation' for education was not recognised by the academics. As one of the academics (Allen) commented above, with many sharing the similar views, the use of the film quote was considered to be 'bad' as it is not 'primary source'; and 'cute' as it is not about the 'scholarship'. This comment seems to elicit an academic convention of referencing (i.e. avoid non-academic source). In other words, academics may prefer to read an 'intellectual style' of writing by students, which is considered acceptable within the academic community. In this case, despite the fact that Tommy's assumption regarding the need to present strong motivation and passion for his proposed field of study does match up with what the academics have stated as their concerns, the way in which Tommy expressed himself did not successfully communicate his intention.

Although the academics did not like the use of film quotes, the use of quotes from people in the academic field of study appears to be acceptable. For instance, elsewhere in his PS, Tommy quoted some words from a statistician in his PS ('CR Rao said, "In the ultimate analysis, all the knowledge is history; In the sense of abstraction, all the science is mathematics; On the basis of rationality, all the judgment is statistics."'). One of the academics commented that he sensed that the student knew something about statistics because the name that Tommy quoted is recognisable in the field. By contrast, quotes from the film 'Dead Poets Society' may not be known to the academics and may even prove to be a hindrance ('it's actually a little bit of a distraction, especially if I don't know who Robin Williams is, or I've never seen the Dead Poets Society', quoted from the other academic, Roy). Roy also suggested that the use of film quote is a 'peculiar' way of writing in the PSs ('there're some idiosyncrasies, peculiarities that are common in ... that occur when people apply from the different countries, quoted from academic interview). This discussion indicates that the ways in which students present their information in texts may lead to different responses from the academics. What the students intend to communicate to the academics may not be always consistent with what the academics come to understand or perceive when reading these texts. Such hidden features of academic writing are not usually made explicit to student writers that remains a complex issue in terms of what is constructed as a desirable style of writing in the admissions discourses.

In relation to the evaluation practices that are associated with the PS, all the academics $(n=19)$ at both universities have indicated that there is no written official checklist for them to follow throughout the evaluation process. One of the examples is as follows:

01 INT: So among the application documents, which part of the application do you 02 think are the most important if I ask you to rank? 
03 Christine: Hmmm (.) hh-. That's hard 'cause I think it's for different (.) purposes.

04 INT: Hmmm.

05 Christine: You know, I have to say hhhhh- (0.5) ((sighing)) this is a ver- I want to be

06 really clear about this. This is an indiv- whatever I respond, however I

07 respond $=$

08 INT: Hmmm.

09 Christine: =is really individual to me.

10 INT: Yeah.

11 Christine: Okay. I can't speak for my colleagues.

As can be seen above, from a CA perspective, Christine seems to be cautious about making a firm statement concerning her views on the most important application documents for application. Although she appears to start responding to my question in line 03, she quickly moves herself away from the continuation of her response in line 05 where she has a long out-ofbreath sound and a short pause, and followed with a statement about her stance towards her upcoming response. This cautiousness when she tried to provide her views on the application documents may be enacted by her sense of membership of an educational institution and her awareness of the relationship between her and me as a researcher. On the one hand, as a member of the leading faculty who takes charge of admissions process, she may be aware of the moral responsibility for what she said. On the other hand, the fact that she was being interviewed by a researcher who was collecting data, may have left her feeling cautious about her responses to my questions. Her response in lines 09 and 11 ('is really individual to me', 'I can't speak for my colleagues') also implies her acknowledgment of varied voices and views among other faculty members. This is especially the case when the academics often review the applications independently prior to the discussion on their opinions as a group.

\subsection{Themes imbued with varied conceptual understandings across institutional contexts 3.2.1 Content and writing in the personal statement Research interests \& a sense of researcher identity} In relation to what the academics expect to see when reading student's PS, the theme of 'research interest and researcher identity' is indicated by those at the US-based university, but interestingly it appears that no references are made in the academics' accounts at the focal UK-based university. However, it should be noted that this is not to suggest that the element of 'research interest and researcher identity' is not important. In fact, such an aspect is heavily stressed as it is probably the most crucial aspect considered by the UK academics when evaluating $\mathrm{PhD}$ applications and the academics commonly look for this type of information to gauge a student's 'intellectual readiness' (term quoted from academic interview). Specifically, the element of 'research interest and researcher identity' occurs when UK academics express their views on the research proposal. Such an orientation is closely associated with the academics' understanding of differences in the documentation that supports an application and their views towards the role of different parts of the application document. Within the UK-based context, such a discourse promotes the view that the research proposal, given the purpose of this document, provides a more detailed description of an applicant's proposed research rather than the PS.

It should also be noted that the practices that are associated with the issue of 'research interest' are different in the two focal institutions. Another discourse that the academics use to construct 
the nature of evaluation is mainly concerned with academics' understanding of the structure of PhD study within their specific academic contexts. As mentioned earlier, students usually embark on their research project as soon as they get accepted into a UK-based institution. In light of this, the UK academics hope to ensure student's research interests match with those of individual academics/supervisors in the department. All the UK academics $(n=9)$ have emphasised the key factor in research connection and a student-supervisor relationship. One of the examples is as follows:

01 Bill: ...if you're taking somebody for a $\mathrm{PhD}$, you're going to have a very close

02 connection with them (students) for four years. So I think let's focus on what is

03 the topic, what's the research area, is it close to mine? Is it linked to the thought in

04 your mind? Can I live with this person for four years intensively? Because if

05 somebody's a full-time student you're going to see them every two weeks for

06 years. So if the actual meaning of what they want to do isn't clear and it's not

07 close to your interests, then, you know, you wouldn't want to do it. I think

08 that's really important.

Unlike the British context, students usually require to complete some coursework in their first two years before writing their doctoral dissertation. The US academics then tend not to consider suitable candidates in terms of specific potential supervisors, but to judge the need in relation to the faculty and programme as a whole, albeit it may vary across programmes and institutions.

\section{Writing sample to gauge student written ability}

The theme of 'the PS serves as a writing sample to gauge student written ability' can be found in the US academics' interview data $(n=10)$ but this is not so much the case in the UK academics' data with regards to discussions of the PS $(n=3)$. When the US academics were asked about their views on the importance of the PS as compared with other parts of the application package, one of the academics responded as follows:

01 Sally: I think [the PS is] the most important thing, yeah, it's the most important thing 02 because you can tell a lot... like you can tell whether or not they can write, you can 03 tell how... whether or not they can make a good argument, um, what's important 04 to them, their interests, you know, all of that so that's... And I really want it to be 05 compelling and draw me in and make me want to work with them.

This is particularly true when the PS is the only written document that is required for the application at the focal US-based institution. In contrast, the UK academics stated that they often look for evidence of the students' ability for writing more often from reading students' research proposals than from PSs ('the PS to be a supplementary document of the research proposal' details given in section 3.2.2). Despite there being variation of documentation for gauging student written ability, faculty members at both universities share similar views that exhaustive writing is expected of students at doctoral level studies.

\subsubsection{The evaluation practices associated with the personal statement}


The interview responses from the US-based academics reveal that the PS serves as only one part of the application for admissions, they tend to read the PS in the context of the whole application package. One of the US academics stated as follows:

01 Max: Um, I think the statement of purpose is really important I think, you know, but then 02 so is the transcript, you know, how the... what's their GPA, you know, I think, you 03 know, the GRE is relevant. I think the people's letters of recommendation are all... 04 they're all really important and that's what makes admissions challenging is that 05 you're trying to balance all those things. And, when you have a really highly 06 selective process, you know, when you have a lot of applications for a very few 07 slots, what it almost comes down to is like, um, I mean among some of these 08 candidates you're just, you're really looking around saying, "Is there any weakness 09 here at all?" ((laughs))

As can be seen above, it is clear that the role of the PS in the US context is positioned in line with other admissions information and such that it may have an effect on academics' perceptions of the PS as academics often use different parts of the application to get a sense of applicants as a whole. In both the UK and the US, the PS is 'preconditioned', as detailed below.

\section{Preconditioned factors}

The academics' interviews at both universities have shown that there are different 'preconditioned factors' that may influence the way in which the academics approach the PS. For instance, the UK academics $(\mathrm{n}=9)$ indicated that they consider the PS to be a supplementary document for the research proposal:

01 Bill: I mean personal statements are useful, but if the research proposal is weak, then 02 the personal statement is often of no interest. You know, "cause sometimes people 03 will tell you a lot about themselves, which is interesting, but then the proposal is 04 no good, then there's no point. So the personal statement is less important than the 05 proposal.

From this perspective, the PS may be considered as less important in comparison to the research proposal in this case. Such a theme is also associated with what I have discussed earlier regarding the structure of the PhD study at the UK-based university. In the US-based one, the preconditioned factor is associated with the GRE score, a standardised test that is an admissions requirement for many graduate schools in the US. It includes measurement of quantitative reasoning, verbal reasoning and analytical writing. All the US academics referred to the requirement of the GRE score when they were asked to compare the PS with other application documents and to also discuss their own evaluation process. One of the US academics stated as follows:

01 Sally: Um, we do look at the GRE score here, although for me personally I really don't 02 value that, and some of my colleagues don't value it at all and some of them do

03 value it, so... but we do, because, you know, it's a prestigious institution and we 04 kind of have to do that... For me it's [GRE] not important because I know the 05 history of the socioeconomic and racial discrimination of the GRE and 
Although the academic's statement above reveals her strong view on what counts as good practice for evaluating the applications, she more or less acknowledges that as the member of a prestigious institution, she still needs to take on board some of the other criteria for application evaluations at the institutional level.

\section{Admissions discourse and power: Individual faculty members vs. institutional practices} Based on UK academics' interviews, it is generally known that the academics possess more leeway with which students they want to accept. This is because the key element for $\mathrm{PhD}$ applications in the UK is to ensure students' research interests match up with the specialism of potential supervisors rather than with people and the programme in general. In contrast, most of the US academics ( 8 out of 10) stated that they feel certain tension and constraints between the practices of faculty members within the individual programmes and those that are endorsed by the school-wide committee, both of which are involved in the admissions process:

01 Vicky: Um, and there's also a very strong mandate... I didn't mention this but

02 increasingly, out of the central office, the Dean, even I guess the University of

03

04 New Wilson (pseudonym) provost, there's a lot of... er, there's more emphasis on

05 the GRE than we used to... we as faculty used to kind of consider that as one piece of the picture but now they're really pretty much disqualifying anybody below, let's say, what is it, 1100 I think. So a combined verbal and math score of 1100 and above, we do look at for sure. We look at those files. And then those that have 1100 or below, we look much less in depth. Because we realise that it's... in fact a few years ago I did put forth one name that had about, I think a total of 600 , because he had other strengths, but I could not make any headway... with the, you know, central administration on the validity of admitting him. And since we have so many, er, qualified applicants above the1100 range, it just didn't seem worth, you know, trying to fight that battle. So I will confess that at this point we pretty much, you know, I pretty much concentrate on those that are above 1100 and that's usually maybe 50 out of the 70 .

As can be seen above, the speaker's shift in the use of personal pronoun is noted here. For example, Vicky used the inclusive form 'we' when discussing the situation concerning the role of the GRE score during the admissions process (lines 03-04). However, in line 05, the personal pronoun 'they' is used to refer to the practice executed by the school-wide committee, which differs from the practices across the faculty (lines 04-08). The use of 'we' again in line 07 ('so a combined verbal and math score of 1100 and above, we do look at for sure') seems to indicate that the faculty members' evaluation practices have been influenced and constrained by the regulation imposed by the school-wide committee. In the same fashion, many other US academics shifted their uses of 'pronouns' from 'I-statements' when talking about their individual practices to 'we-statements' when stating the influence from the school-wide committee during the admissions process. The academic's account above also shows an example of fighting for a student whose GRE was low but failing to secure a place for the student when she negotiated with the school-wide committee (lines 09-11). This example appears to legitimise 
the strict regulation imposed by the school-wide committee and implies a certain 'power' issue during the admissions process. Here, a discourse at an institutional level can be identified which promotes the view that standardised test scores, such as GRE, may be seen as prerequisites for admissions at a prestigious institution. However, the competing discourses that individual faculty member brings to the institution may engender certain negotiations and even tension during the admissions process.

Interestingly, two of the US academics from a group of ten pointed out that they do not know how to evaluate the PS without being given other parts of the application document to also look over (GRE score in particular). These two academics are from the same programme (Policy Research) where the GRE score is highly valued over the rest of the application document. One of the academics stated as follows:

01 Roy: The screening process depends heavily on the GRE scores and for us high

02 quantitative scores are essential. Good verbal scores are desirable...so we rely on

03 both but the quantitative is weighted more ...Yeah, GRE is the first cut. If the

04 scores are too low we don't bother going any further...'cause the kid is just not

05 going to survive.

As can be seen above, Roy's statement suggests that in the programme where he is based, the quantitative aspect of the GRE scores is considered as crucial as it serves as an indicator of a student's ability in Mathematics/Statistics. In this case, if the students' GRE scores are too low, their PSs may not even be evaluated in the admissions process.

It is clear that many other institutional considerations were coming into play during the admissions process. There is a possibility that the criteria for evaluating the application documents are not related solely to their quality. Such a view has been reinforced by many of the academics at the US-based institution. One of the academics stated as follows:

01 Ariel: I mean I think that like the things you're bringing up, like yeah, that totally reads 02 out like, you know, 60 people, you're like, "No you're not a good fit." "You're 03 not serious." But then like those top ten people, it comes down to stuff that really 04 has nothing to do with the student any more, whatsoever. It has to do with like 05 how many other students are in the programme, who came last year? Like did we 06 take four people who were really interested in Second Language Acquisition?

07 Well let's try to take some people who are interested in Sociolinguistics to

08 balance. You know what I mean? Like that's completely about like the 09 programmes ideas about balance [...]. That's about like institutional constraints...

The account above implies that at a certain stage (e.g., the final stage) in the admissions process, the student's application is no longer the focus of the evaluation (lines 03-04). This is especially the case when many of the applicants have equally strong qualifications and the admissions committee finds it difficult to select one applicant over another. In this case, the consideration would then focus on other departmental and institutional priorities.

\section{Discussion}


This exploratory study, unlike previous examinations of PSs, focuses particularly on academics' views of the PS across institutions. The multilayered treatment of interview data has foregrounded not only the content which shows how different evaluation practices are in play across the institutions but also ways in which the academics discussed their evaluation process. In departing from existing genre studies on PSs, its comparative angle has contributed to our understanding of how the bureaucratic admission procedures and the epistemological assumptions of particular discourse communities have shaped the ways in which academics come to evaluate an admissions document. The effect of 'preconditioned factors' to the PS, as shown in this study, has also echoed the view that the role of the PS may not always be straightforward in the evaluation process (e.g., Barton et al., 2004; Samraj \& Monk, 2008). It is important to understand the PSs in particular, and academic writing more generally within a wider institutional approach.

This study can potentially make a useful contribution to the growing interest in genres and practices. For instance, the academics' responses to the students' PSs can also be extended to include the design of academic writing workshops that attempt to draw students' attention to writing issues such as audience expectation and the conventions of target academic programme/community, of the kind that more often than not, are slipped out of applicants' mind. Swales and Feak (2011), in their textbook on the supporting genres, have suggested some tasks which can be adapted for classroom discussion to raise students' awareness of the difference between the SOP and the PS, and their audience and self-positioning. The aspect of institutional practices and considerations shown in this current study can complement their volume to enhance students' sensitivity to institutional variations. Swales, in his conversation with other researchers about the PS genre, stated that one of the aspects that attributes to students' failure in their application is the epistemological 'leap', especially from Masters to a $\mathrm{PhD}$ (cited in Barton $\&$ Brown, 2004). The results of this current study, albeit given the constraints on my data, shall help shed light on the prospects of doctoral studies in that the inclusion of research-related information in the PS is often valued by academics as it gives the impression of having a sense of identity as a researcher. Such kind of scientific epistemology, which goes beyond general advice and admissions instruction available from the websites, is often not made explicit to applicants and as such merits further exploration because of its distinctive feature.

The discussions on academics' perceptions of the PS in this study have yielded an important direction for further research in this line of work. Specifically, the academics' accounts of their expectation and assessment of the quality of writing in student admissions essay, such as the PS and research proposal, imply that certain features must be shared between the PS genre for doctoral study admissions and academic writing within the targeted academic setting. Although the PS serves a different purpose to student writing in the context of university education, such a finding reinforces my earlier argument that the PS can be contextualised as a form of 'academic' writing since its purpose is to communicate with an academic audience and it is also considered as a type of writing sample that academics will use to evaluate a student's written ability, as shown in this current study. In this sense, it can be inferred that the boundaries amongst different modes of discourse or text types seem to be blurred. It is important for further research to be conducted in order to determine the 'personal', as well as the 'academic', aspects of the PS. In fact, Swales (2009) has pointed out that the title of 'personal statement' for admissions essay, "somewhat over-emphasizes the life story element" (p. 7). This standpoint indicates that the PS 
writing should follow certain 'academic' conventions valued by the targeted academic community. Yet, it still remains unclear as to whether this would be the case across the board for the PSs submitted for different levels of education and within diverse institutional contexts (e.g., research-intensive vs. teaching-oriented institutions). This study has shown a productive approach for further research to understand the different and often implicit features of the PS across different disciplines, programmes, and institutional contexts.

\section{References}

Baker, C. \& Johnson, G. (1998). Interview talk as professional practice, Language and Education, 12(4), pp. 229-242.

Barton, E., \& Brown, R. (2004). Personal Statements: A Conversation with John Swales and Chris Feak. Issues in Writing, 15(1), 5-30.

Barton, E., Ariail, J., \& Smith, T. (2004). The professional in the personal: The genre of personal statements in residency applications. Issues in Writing, 15(1), 76-124.

Bekins, L. K., Huckin, T. N., \& Kijak, L. (2004). The personal statement in medical school applications: Rhetorical structure in a diverse and unstable context. Issues in Writing, 15(1), 56-75.

Brown, R. M. (2004). Self-Composed: Rhetoric in psychology personal statements. Written Communication, 21(3), 242-260.

Burnard P. (1991). A method of analysing interview transcripts in qualitative research. Nurse Education Today, 11, 461-466.

Dick, P. (2004). Discourse analysis. In C. Cassell \& G. Symon (ed.). Essential guide to qualitative methods in organizational research, (pp. 203-213). London, UK: Sage Publications.

Ding, H. (2007). Genre analysis of personal statements: Analysis of moves in application essays to medical and dental schools. English for Specific Purposes, 26(3), 368-392.

Fairclough, N. (1992). Discourse and Social Change. Cambridge: Polity Press.

Fairclough, N. (2003). Analysing discourse: Textual analysis for social research. New York: Routledge.

Green, J., \& Bloome, D. (1997). Ethnography and ethnographers of and in education: A situated perspective. In J. Flood, S. Brice Heath, \& D. Lapp (Eds.), Research on teaching literacy through the communicative and visual arts (pp. 181-202). New York: Macmillan.

Heritage, John. (2005). Conversation analysis and institutional talk. In K.L. Fitch \& R.E. Sanders (ed.) Handbook of language and social interaction, (pp. 103-147). New Jersey: Lawrence Erlbaum Associates, Inc.

Hyland, K., \& Tse, P. (2005). Hooking the reader: a corpus study of evaluative that in abstracts. English for Specific Purposes, 24(2), 123-139.

Johnstone, B. (2008). Discourse analysis. Malden, Massachusetts: Blackwell Publishing.

Lea, M. R., \& Street, B. V. (1998). Student writing in higher education: An academic literacies approach. Studies in Higher Education, 23, 157-172.

Lillis, T. (2008). Ethnography as Method, Methodology, and "Deep Theorizing": Closing the Gap Between Text and Context in Academic Writing Research. Written Communication, 25(3), 353-388.

Roberts, C. (n.d.). Qualitative research methods: Introduction. King's College London. Available from: http://www.kcl.ac.uk/innovation/groups/ldc/knowledgetransfer/DATA/introduction.pdf [Accessed 28/07/2013]. 
Russell, D., Lea, M., Parker, J., Street, B., \& Donahue, T. (2009). Exploring Notions of Genre in "Academic Literacies" and "Writing Across the Curriculum": Approaches Across Countries and Contexts. In C. Bazerman, A. Bonini, \& D. Figueiredo (ed.) Genre in a Changing World, (pp. 395-423). Fort Collins, Colorado: The WAC Clearinghouse and Parlor Press.

Samraj, B., \& Monk, L. (2008). The statement of purpose in graduate program applications: Genre structure and disciplinary variation. English for Specific Purposes, 27, 193-211.

Swales, J. M. (1990). Genre analysis: English in academic and research settings. Cambridge: Cambridge University Press.

Swales, J. M. (2009). Worlds of genre - metaphors of genre. In C. Bazerman, A. Bonini, and D. Figueiredo (ed.). Genre in a Changing World, (pp. 3-16). Fort Collins, Colorado: The WAC Clearinghouse and Parlor Press.

Swales, J. M., \& Feak, C. B. (2011). Navigating academia: Writing supporting genres. Ann Arbor: University of Michigan Press.

Swales, J. M., \& Leeder, C. (2012). A reception study of the articles published in English for Specific Purposes from 1990-1999. English for Specific Purposes, 31(2), 137-146. 